\title{
Application of surface frequency functions to assess the state of the kinematic pair elements
}

\author{
Maciej Matuszewski ${ }^{1 *}$, Małgorzata Słomion ${ }^{1}$, Janusz Musiał and Andres Bustilo ${ }^{2}$ \\ ${ }^{1}$ University of Science and Technology in Bydgoszcz, Faculty of Mechanical Engineering, 85-796 \\ Bydgoszcz, Poland \\ ${ }^{2}$ University of Burgos, Department of Civil Engineering, Avda Cantabria s/n, Burgos 09006, Spain
}

\begin{abstract}
In this paper the possibility of using frequency functions of the kinematic pair surface layer elements was analyzed for evaluation of the surface layer condition. The function of spectral power density and autocorrelation which were accepted for analysis was characterized. Evaluation of the elements condition was made on the quantify way as changes in degree of isotropy and in the qualitative way based on the graphs of the analyzed frequency functions. After tribological tests the surface structures were adopted to assess the changes. Spectral graphs for structures without cooperation (directly after-machining) and for the different friction distance, were analyzed. Conditions during tribological tests were taken as permanent. The determined degree of isotropy basis on the frequency functions and received graphs of spectra power density function and autocorrelation become useful in evaluation of the surface layer changes during its transformation.
\end{abstract}

\section{Introduction}

Each technical object is characterized by a set of functional qualities. In case of machines their capabilities, e.g. durability and reliability are result of the features represented by the elements that create the structural combination of the object. These combinations are a set of kinematic pair so it can be concluded that the aforementioned set of functional qualities is determined by the features of individual kinematic pairs.

As the numerous research shows [1-8] it was found that the functional characteristics depend to the greatest extent of the surface layer condition, which is formed throughout the entire production process. Condition of the surface layer is mainly determined by the surface stereometry, i.e. the outer part of the surface layer. The stereometric shape of the surface is defined as the surface geometrical structure. The stereometric surface structure is a set of surface micro roughness which are traces of machining operation or effects of the wear process. Roughness, waviness, degree of surface isotropy, traces directionality of machining, shape deviations and surface defects are assumed as the basic quantities describing the geometric surface structure $[9,10]$. Depending on the distribution of the characteristic elements of the geometric surface structure, the surface may be anisotropic or isotropic.

The reason for functionality loss of the elements forming friction nodes is limited wear resistance their surface layer on the damaging effects of external forces. Influence of these factors (mechanical, thermal, chemical, electrical) over the cooperation of kinematic pair, causes changes in the surface layer. These changes are generally the reason of loss kinematic pair ability to fulfill the design-related functions in a different grade.

The evaluation of the surface layer cooperating elements changes is described by quantitative and qualitative changes. Various roughness parameters, weight loss, changes in

\footnotetext{
*Corresponding author: matus@utp.edu.pl
} 
linear dimensions are the quantities accepted for the description of the quantitative changes [11-14]. Whereas, the evaluation of qualitative changes is made among others on the basis of photographs of the examined surfaces or spectral analyzes of these surfaces $[10,15]$. On the basis of qualitative analysis we get information about general features of the geometric surface structure (roughness and directionality), effects of wear (traces of wear) and type of possible damage.

In this paper frequency characteristics were described for the quantitative and qualitative analysis of the geometric surface structure condition, which describe the frequency structure of the tested surfaces.

\section{Frequency surface functions}

Space-frequency functions are commonly used and these are mainly spectral power density and autocorrelation. Frequency analysis is a source of information of the manufacturing process. Articles [16-19] present examples of processing monitoring with the use of frequency functions and conclusion on these grounds about various process factors, e.g. machine cutting forces and their components, whereas in papers $[20,21]$ these functions were used as an information about cutting edge condition of the cutting tool and machine tool. On the basis of these functions, it is possible to determine isotropy degree of the geometrical surface structure.

Functions of spectral power density and autocorrelation describe the frequency surface structure. Functions of spectral power density and autocorrelation during the manufacture and shaping the geometric surface structure, as well as wear process are useful in an analysis the surface topography.

The surface autocorrelation function is a symmetrical real-valued function. Its value at zero dislocation is the maximum value equal to the variance of the irregular crests heights. It is a measure of the dependence of the data value in one position from their value in the second position and reacts very sensitively to any surface structure interferences [22, 23]. In research, depending on their purpose, one of the above functions is generally used. It results from mutual relations, namely the power spectral density function is a Fourier transform of the autocorrelation function. The power spectral density function illustrates how the deviation of surface irregularities decomposes with the surface frequency.

Generally, on the basis of the spectral analysis of the surface structure, we can draw the following conclusions $[22,23]$ :

- low frequency components are more significant in the spectral analysis, the role of high frequency components is negligible,

- on the periodic surfaces in one or two perpendicular directions, the energy is concentrated in the space of proper frequency along the same directions,

- on the anisotropic surfaces energy is concentrated along the perpendicular direction to the structure directionality (symmetry),

- $\quad$ in case of mixed anisotropic surfaces with the participation of a short-wave random component, decisive are long-term components defining surface anisotropy,

- in anisotropic random surfaces, characteristic features of random noise appear the background of clearly dominant components with low frequency, while the surface structure retains anisotropy and directionality,

- $\quad$ random noise dominates in random isotropic structures and the features of anisotropy are negligible.

\section{Analysis of exemplary applications of frequency functions}

Selection of the various surface roughness parameters to determine condition of the kinematic pair surface layer elements is carried out on the basis of scientific research, statistical correlation between them and availability of equipment. Selected parameters 
which describe the surface structure with reference to its functional qualities may not be always clearly classified. Because of this the choice is always more or less subjective. Therefore, use of the geometric surface structure description based on its mathematical functions, especially on the surface autocorrelation or spectral power density seems to be a procedure without a subjective model parameters selection error. Frequency analysis makes it possible to assess the geometric surface structure independently from machining type.

It can be confirmed by an comparative analysis of the geometric surface structure presented in this paper [23]. The analyzed surfaces (Fig. 1) were obtained after the following processing:

- throwing at high cutting speed,

- longitudinal grinding,

- deep grinding,

- $\quad$ superfinish.
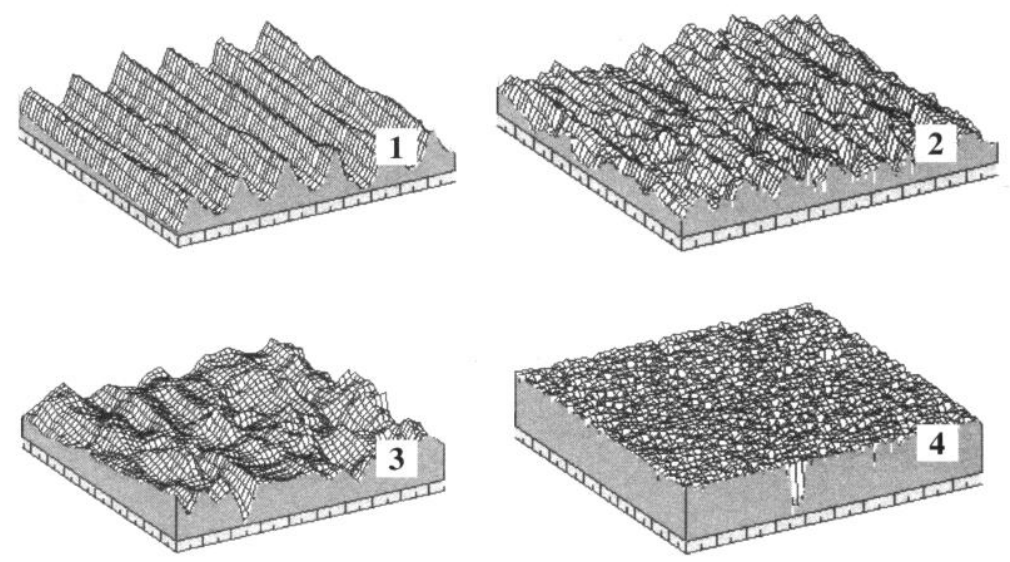

Fig. 1. Obtained surfaces by: 1 - throwing, 2 - longitudinal grinding, 3 - deep grinding, 4 superfinish [23]

The surface after throwing and longitudinal grinding is clearly anisotropic, the surface after superfinish is isotropic, while the surface after deep grinding is mainly anisotropic.

Figure 2 presents the graphs of the autocorrelation function of these surfaces and figure 3 - the degree of isotropy in form of rose of directions.
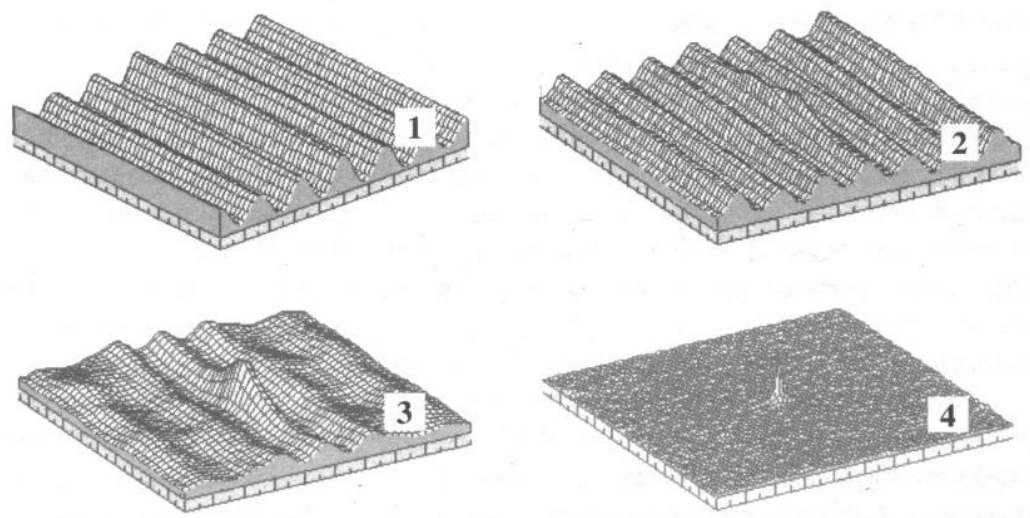

Fig. 2. Graph of surface autocorrelation function (surface designation as in Fig. 1) [23] 

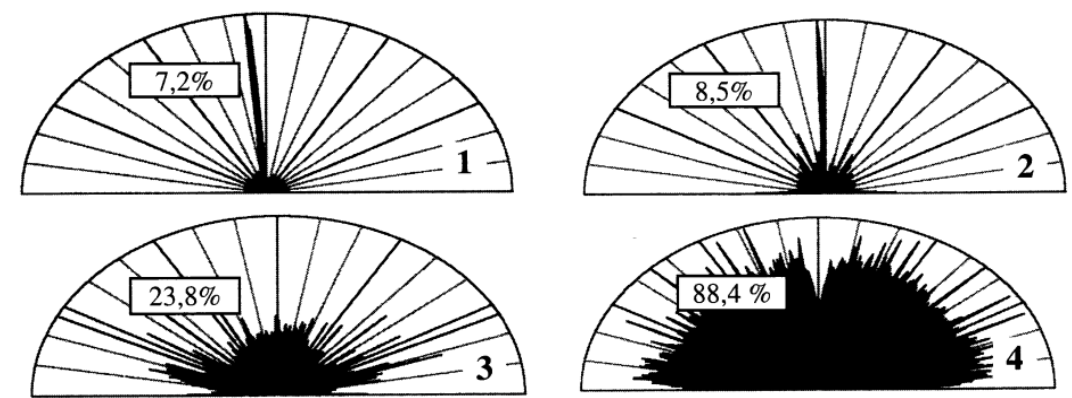

Fig. 3. Degree of surface isotropy (surface designation as in Fig. 1) [23]

At the presented figures the autocorrelation function graphs change can be notice and the isotropy degree can be specified precisely on the basis of this function depending on the analyzed surface topography. Account the surface isotropy determined from the frequency function can be a factor contributing to better evaluation the condition of analyzed surface, especially of its potential functional qualities and tribological characteristics.

In order to verify the usefulness of spectral analyzes evaluation for quantitative and qualitative changes occurring in the surface layer cooperating elements experimental studies were carried out. Specimens was subjected to tribological tests and the degree of isotropy was accepted for quantitative evaluation of changes taking place but for the qualitative assessment graphs of spectral power density was accepted as well as autocorrelation function of the tested structures on a different friction distance. Conditions during tribological tests were mosty taken as permanent. Specimens and counter-specimen were cooperating in the lubricating medium which was machine oil (L-AN 68) and the operating parameters were as follows: relative motion speed: $2,9 \mathrm{~m} / \mathrm{min}(0,05 \mathrm{~m} / \mathrm{s})$, loads: 300,450 and $600 \mathrm{~N}$ in the quantitative analysis and $600 \mathrm{~N}$ in the qualitative analysis. For this loads the theoretical pressure in contact zone was respectively: 1; 1,5 i $2 \mathrm{MPa}$. Cooperation angle between characteristic directionality of specimens and counter-specimen was $0^{\circ}$. Specimens were made of $102 \mathrm{Cr} 6$ steel, whereas counter-specimen was made of $\mathrm{X} 210 \mathrm{Cr} 12$ steel. Hardness of counter-specimen was 50\% higher in order to enable changes on the specimens surface. Hardness values were respectively $60 \mathrm{HRC}$ and $40 \mathrm{HRC}$.

Figure 4 shows changes of the geometrical surface structure isotropy degree in funtion of friction distance.

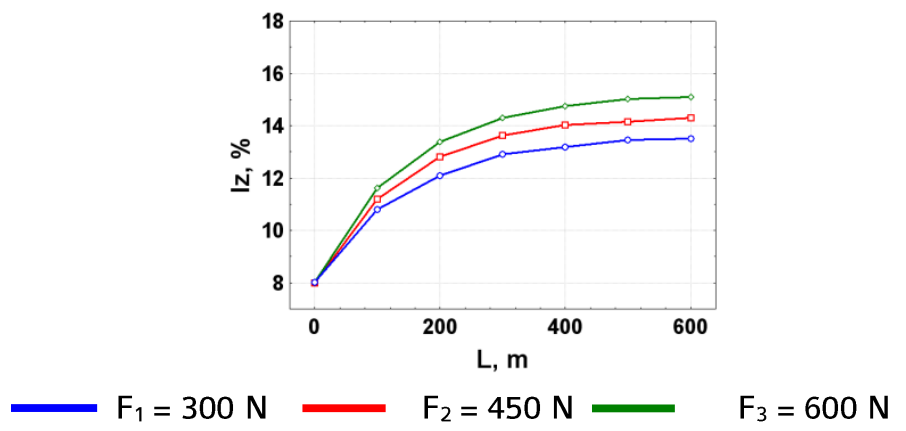

Fig. 4. Change of isotropy degree $I z$ in function of friction distance $L$ for different loads

On the basis of graphs it is possible to draw conclusion that the isotropy degree changes with the increase in friction distance. The changes also depend on realized loads and they are the result of surface layer structure change during operation. The value of isotropy level is getting higher which may have the following interpretation: the formation of the 
stereometric structure is "flattened" and the symmetry of this configuration increases. Single pix and microroughness crest undergo partial or total abrasion. Traces of machining decided about directions of shaping and together with increase of isotropy degree they get distorted. General assessment of description of the surface layer changes on the basis of isotropy degree confirmed the usefulness of these parameter use in the analysis of changes taking place in kinematic pair surface layer elements during operation.

In figure 5 and 6 the quality analysis on the basis of the graphs of the power spectral density function and autocorrelation for selected friction distances (100, 500 and $2000 \mathrm{~m})$ was presented.

a)

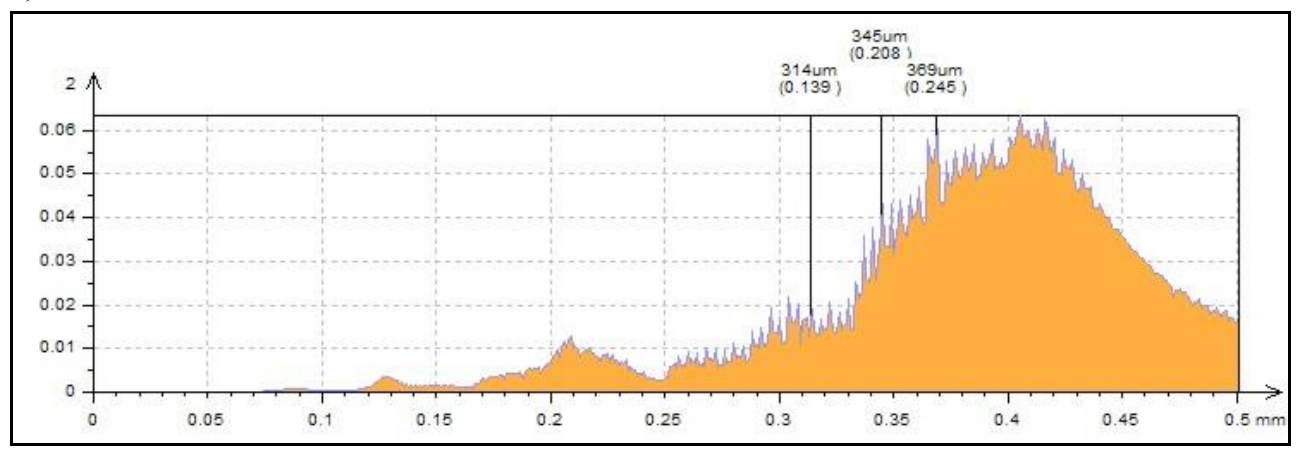

b)

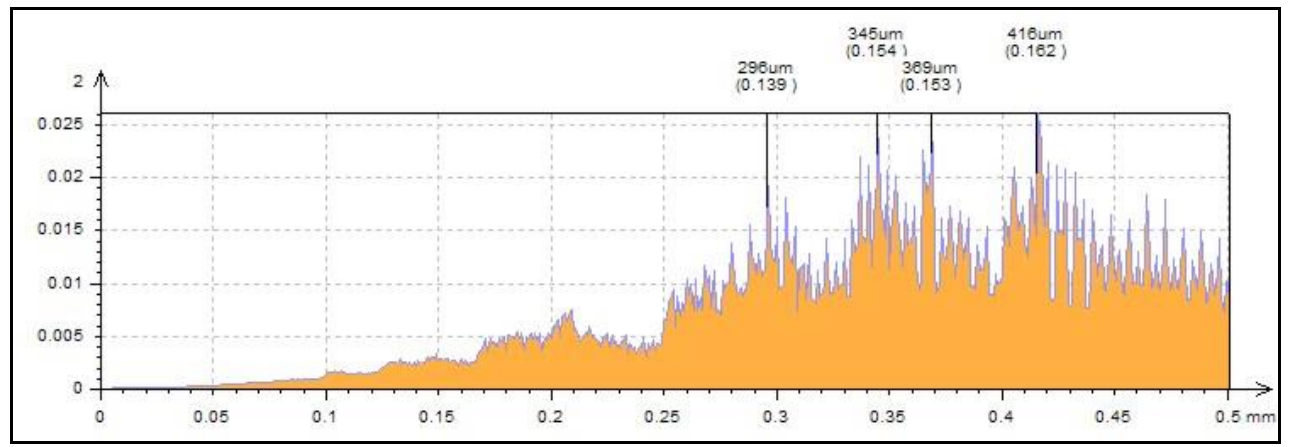

c)

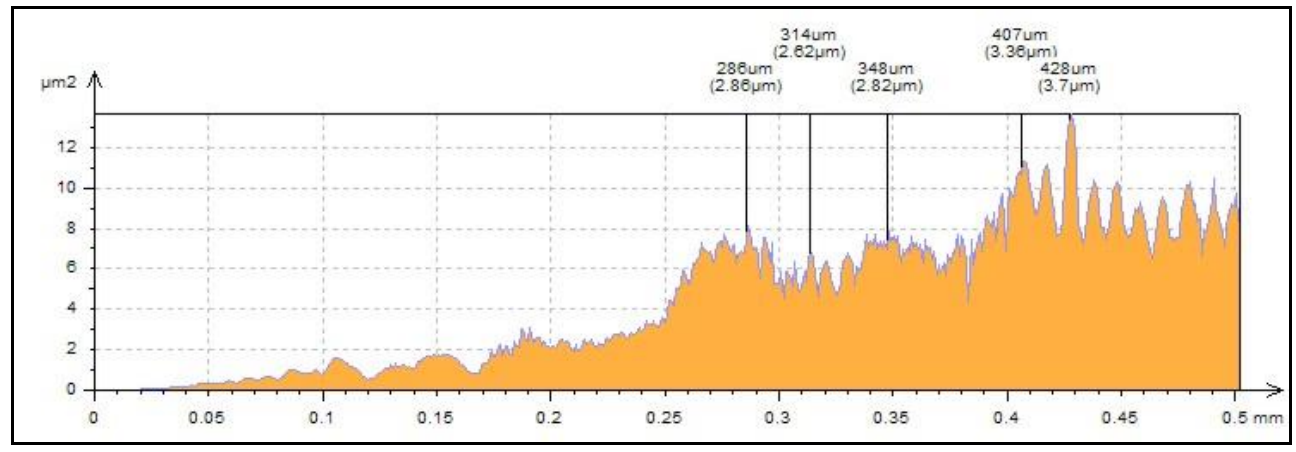


d)

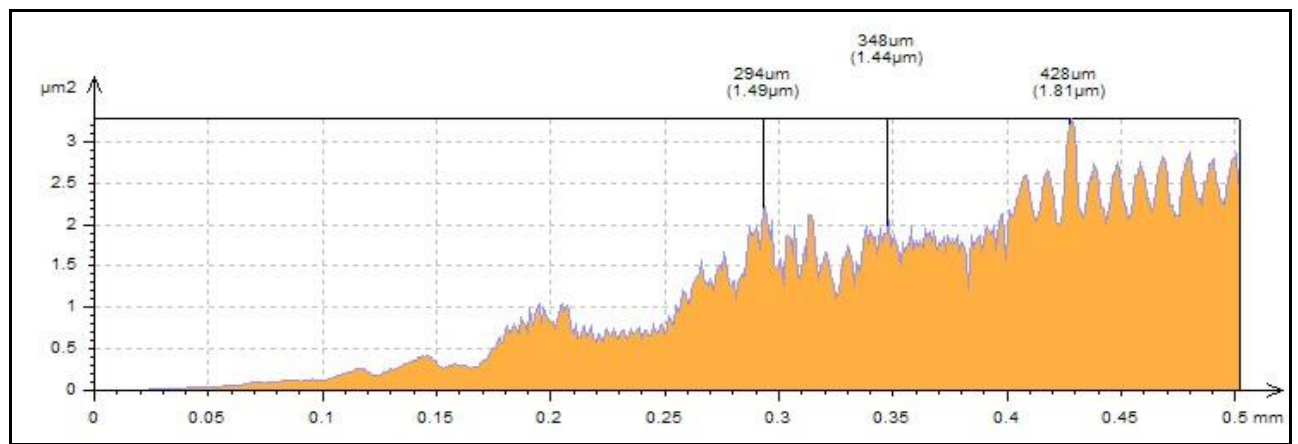

Fig 5. Graphs of the power spectral density function for the following friction sections: a) 0 (without the cooperation), b) 100 , c) 500, d) 2000 meters

The above graphs shows how the spectral power density function changes at the particular cooperation stages. At the beginning (Fig. 1a), when the specimen did not cooperate one dominant may be noticed in the graph which follows from the surface character (defined directionality of geometric surface layer) and hence the determined way of machining and accepted parameters. In the remaining graphs there is no longer one dominant and this is due to changes arising as a result of surface cooperation. Traces of treatment disappear and the direction of these traces is not so clearly privileged.

a)

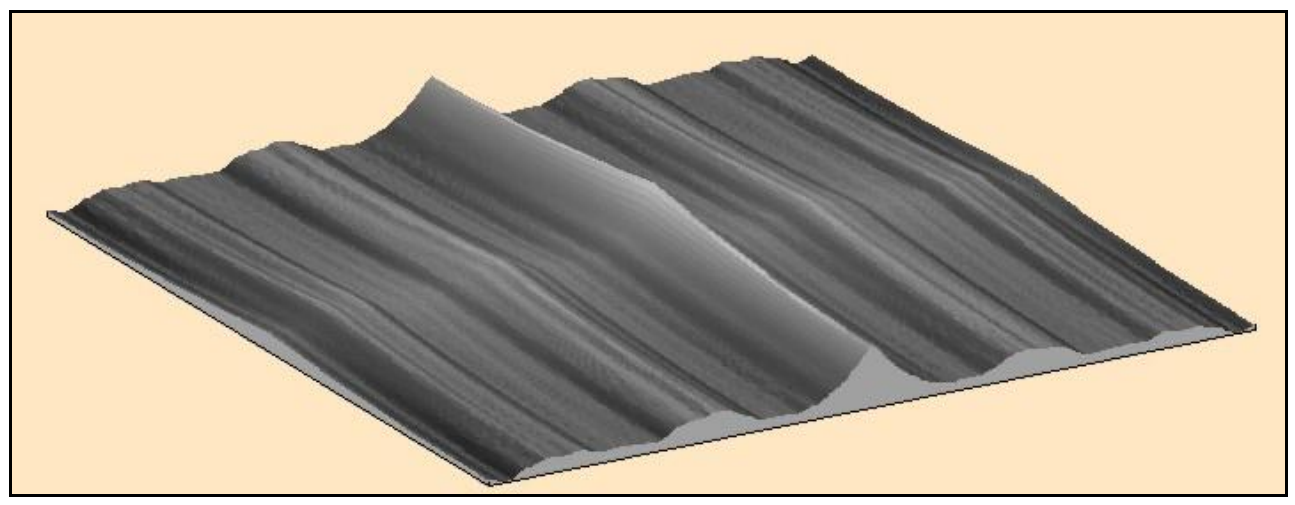

b)

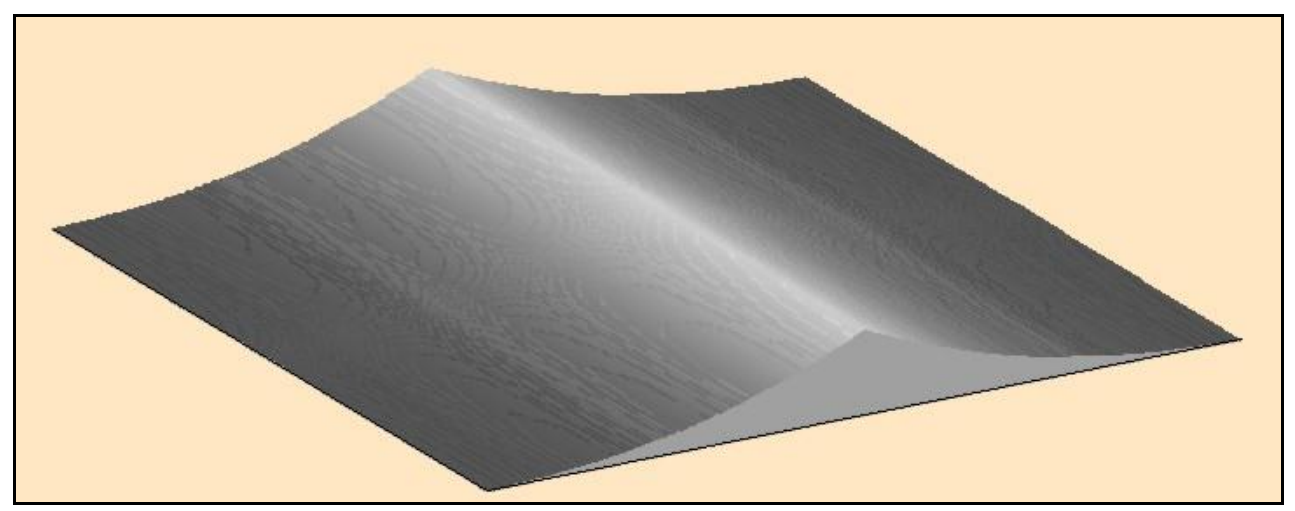

c) 


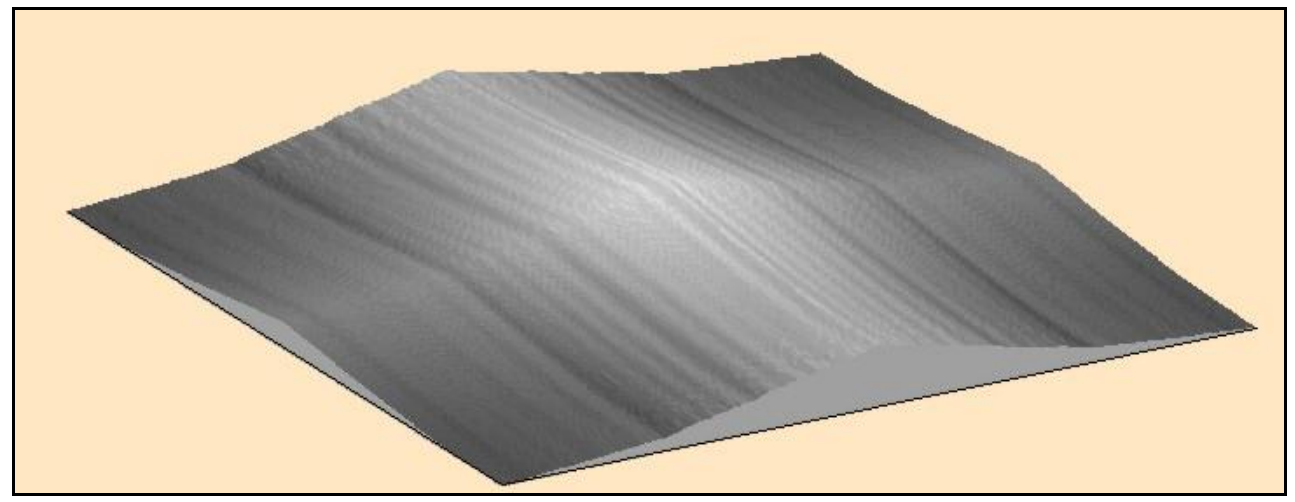

d)

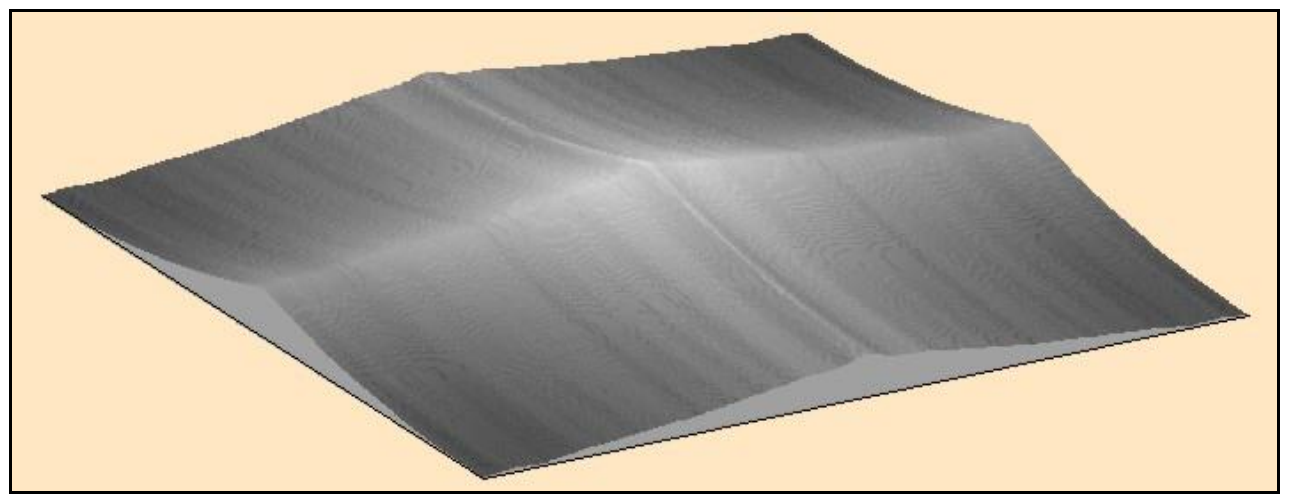

Fig. 6. Graphical form of the autocorrelation function for the following friction segments: a) 0 (without cooperation), b) 100, c) 500, d) 2000 meters

From the presented drawings one can observe how the geometric structure of the anisotropic surface (Fig. 2a) changes into a mixed structure without a clearly privileged direction, but with the still existing directivity of the geometric surface structure (Fig. 2d). However, no full change in the isotropic structure is observed, with complete disappearance directionality of the geometric surface structure.

\section{Summary}

On the basis of the analyzes carried out in this paper, the usefulness of surface frequency functions to assess the condition of the surface layer of cooperating elements of kinematic pairs was found. Due to the subjective selection to assess the state of the surface structure of parameters that characterize it, e.g. roughness parameters, the use of surface frequency functions for this assessment seems to be a more favorable solution, not subject to the error of subjective model selection of parameters. The obtained graphs of the power spectral density and autocorrelation proved to be useful in qualitative assessment of surface structure. It is possible to analyze the occurring changes of the surface layer during its transformation.

In order to provide a more complete quality assessment of the surface layer of cooperating elements, it would also be necessary to analyze the tested surfaces based on their $2 \mathrm{D}$ or $3 \mathrm{D}$ images. It is then possible to additionally conclude about the details of surface stereometry. 


\section{References}

1. J. H. Horng, J. F. Lin, K. Y. Li, Effect of surface roughness on stell roller scuffing. Wear, 184, 203-212 (1995)

2. T. Kałaczyński, M. Łukasiewicz, J. Musiał, R. Polasik, M. Szczutkowski, N. Dluhunovych, J. Wilczarska, T. Kasprowicz: Analysis of the diagnostic potential research thermovision in the technical state of combustion engine injectors assessment, 24th International Conference Engineering Mechanics 2018, Svratka, Czech Republic, Book of full texts, Institute of Theoretical and Appiled Mechanics of the Czech Academy of Sciences, Prague, 357-360 (2018)

3. J. Krawczyk, Tribological properties of selected structural steels (Wtaściwości tribologiczne wybranych stali konstrukcyjnych). Tribologia, 4, 223-233 (2010)

4. E. Mańka, M. Słomion, M. Matuszewski, Constructional features of ropes in functional units of mining shaft hoist. Acta Mechanica et Automatica, 12, 1, 66-71 (2018)

5. M. Matuszewski, T. Mikołajczyk, D. Yu. Pimenov, M. Styp-Rekowski, Influence of structure isotropy of machined surface on the wear process. International Journal of Advanced Manufacturing Technology, 88, 9, 2477-2483 (2017)

6. M. Matuszewski, M. Styp-Rekowski, Influence of texture direction of kinematic pair elements surfaces on service operated layer transformation. Tribologia 4, 87-97 (2006)

7. Ł. Muślewski, Evaluation Method of Transport Systems Operation Quality. Polish Journal of Environmental Studies, 18, 2A, Hard Olsztyn, Olsztyn (2009)

8. Ł. Muślewski, M. Pająk, B. Landowski, B. Żółtowski, A method for determining the usability potential of ship steam boilers. Polish Maritime Research, 4 (92), 23, 105-111 (2016)

9. T. Burakowski, T. Wierzchoń, Metal surface engineering (Inżynieria powierzchni metali), (Publ. WNT, Warszawa, 1995)

10. R. Górecka, Z. Polański, Metrology of the surface layer (Metrologia warstwy wierzchniej), (Publ. WNT, Warszawa 1983)

11. A. Bustilo, D. Yu. Pimenov, M. Matuszewski, T. Mikołajczyk, Using artificial intelligence models for the prediction of surface wear based on surface isotropy levels. Robotics and Computer Integrated Manufacturing, 53, 5, 215-227 (2018)

12. M. Łukasiewicz, T. Kałaczyński, J. Musiał, J. Shalapko, Diagnostics of buggy vehicle transmission gearbox technical state based on modal vibrations. Journal of Vibroengineering, 16, 6, 3137-3145 (2014)

13. M. Styp-Rekowski, Geometrical constructional features of special rolling bearings against their exploitational properties, Proceedings of IV th Symposium INTERTRIBO '90, C, 93-96 (1990)

14. M. Styp-Rekowski, E. Mańka, M. Matuszewski, M. Madej, D. Ozimina, Tribological problems in shaft hoist ropes wear process. Industrial Lubrication and Tribology, 67, 1, 47-51 (2015)

15. P. Pawlus, Surface topography: measurement, analysis, impact (Topografia powierzchni: pomiar, analiza, oddziatywanie), (Publ. Rzeszow University of Technology, Rzeszów, 2006)

16. W. Lubimow, K. E. Oczoś, Selected issues of shaping surface irregularities in machining processes (Wybrane zagadnienia ksztaltowania nierówności powierzchni $w$ procesach obróbkowych). Mechanik, 3, 81-84 (1997)

17. B. Nowicki B., Geometric structure: surface roughness and waviness (Struktura geometryczna: chropowatość i falistość powierzchni), (Publ. WNT, Warszawa, 1991)

18. B. G. Rosen, R. Ohlsson, J. Westberg, 1995. Interactive surface modelling, an implementation of an expert system for specification of surface roughness and 
topography. International Journal of Machine Tools and Manufacture, 35, 317-324 (1995)

19. D. J. Whitehouse, Process and quality control using surface finish. Proceedings $6^{\text {th }}$ Symposium IMEKO Metrology for quality control in production, Vienna, 699-710 (1998)

20. J. Raja, Field testing of machine tool diagnostic techniques using surface metrology. Annals of CIRP, 32, 503-506 (1983)

21. Y. S. Wong, A. Y. C. Nee, X. Q. Nee, X. Q. Li, C. Reisdorf, 1997. Tool condition monitoring using laser scattering. Journal of Material Processing Technology, 63, 205210 (1997)

22. K. E. Oczoś, W. Lubimow, Determinism and randomness of surface geometric structures (Determinowość i losowość struktur geometrycznych powierzchni (SGP)). Pomiary Automatyka Kontrolna, 10, 2002, 4-6 (2002)

23. K. E. Oczoś, W. Lubimow, Surface geometric structure (Struktura geometryczna powierzchni), (Publ. Rzeszow University of Technology, Rzeszów, 2003) 